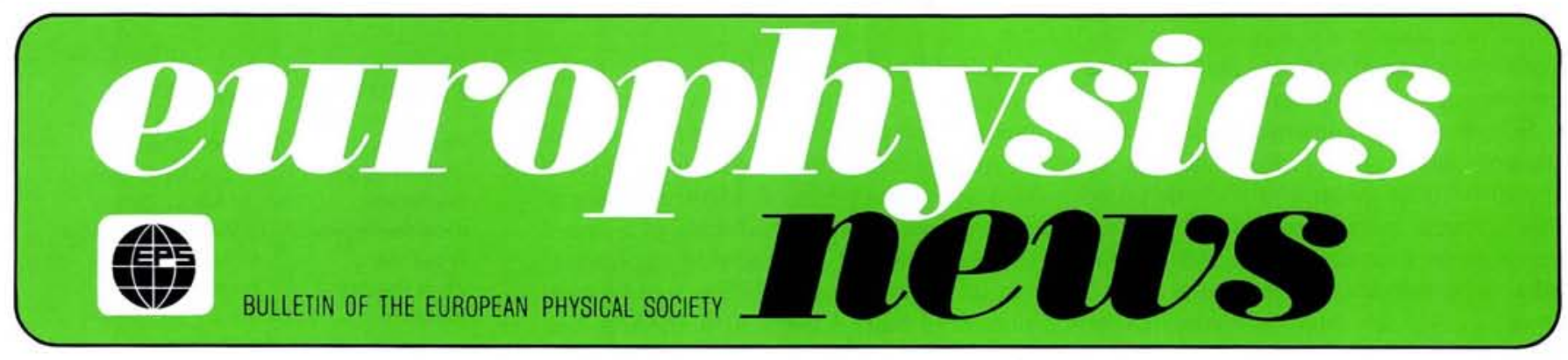

J.A.

\title{
Council in Copenhagen
}

Following the Symposium on International Facilities for Physics Research (an account of which will be given in a later issue) and various meetings of EPS Advisory Committees and the Executive Committee, Council met in Copenhagen on 24-25 March 1983. The sessions were held in the resplendent headquarters of the Royal Danish Academy of Sciences and Letters and the social programme included a reception by the City Council in the equally imposing City Hall.

It was a meeting at which delegates could concentrate on the major activities of the Society and its forward programmes without the overriding worry of a critical financial situation. Not that the Society could lean back and relax, but the efforts of the past 12 months had resulted in 1982 yielding a surplus, and with the surplus forecast for 1983 , we should be in sight by the end of the year of being able to pay off our accumulated deficit. Contributing to the improved position in 1982 had been specific donations, notably that of $£ 15000$ from the UK Institute of Physics and the increase in the number of Associate Members. This latter would have an even greater impact in 1983, added to which was the increase in unit fee which took effect from the beginning of this year. There were however other positive factors such as the profit from the sale of Europhysics Conference Abstracts, including a sizeable return from the sale of back numbers, and the contract for secretarial services negociated with SPIE. Moreover, the European Journal of Physics had now reached the break even point and the Society would be able to pay off its share of the accumulated deficit on this project through its income from profits to be expected in future years.

Taking the countries with convertible currencies only, one could still note big differences in support from country to country, measured for example as a function of GNP, with firmly in the lead the Netherlands and Switzerland but with Finland not far behind. The Finance Committee had, in consequence, established targets which would form the basis for future campaigns.

For the countries with non convertible currencies, the problem of using efficiently the resources persisted, but the opening of an office in Budapest (q.v.) could provide at least a partial answer.

Particularly important was the need to keep up the pressure on recruitment for Individual Members so as to compensate the inevitable wastage and preserve the balance between the various membership classes. Divisional conferences were identified as being the natural focus for recruitment drives.

\section{Advisory Committees}

Vigorous activity was reported in all the Advisory Committees out of which could be noted: ACAPPI, a pamphlet on "Promoting Applications of Physics" was to be published shortly; the next meeting of the Associate Members was planned for the Spring of 1984 as a two-day event with a special symposium included; arrangements will be finalised for the election of their delegates to Council following approval of the amendment to the Constitution (see page 12) whereby the Associate Members will in future be represented in Council. Conference Committee: 10 EPS conferences (including one Europhysics School) were being organised by the EPS Divisions in 1983 and 36 were being sponsored by EPS - a few less than last year but the difference could be accounted for as statistical fluctuations in a stable situation. Physics and Education: Replies to the enquiry covering tertiary education had been received, the analysis of which would be published in Europhysics Education News. Under the Teaching Abroad scheme one teacher from Poland and another from Turkey would be going to Sweden; ideas are being explored for an international collaboration on research into the teaching of physics. Physics and Society: Several pro- jects are being worked on in parallel covering the training of Ph. D. s. - a follow up to the Erice Seminar in 1981; questions relating to the popularisation of science and the history of science; alternative energy sources. Under the stimulus of this Committee the statement published in Europhysics News in the July 1982 issue had been sent to the principal negotiators at the Geneva disarmament talks and had been courteously acknowledged by both. There was little more that EPS could do collectively. All of these Committees together with the Divisions were actively concerned in the preparation of the 6th General Conference which will be held in Prague from 27-31 August 1984. Publications: Apart from the Europhysics Letters project (q.v.) this committee had been studying the problem of the purchase of physics journals by countries with a balance of payments problem (and especially Poland). Libraries everywhere were under financial pressure but a partial solution could lie in an effective use of UNESCO coupons. An enquiry will be held to see how EPS can help.

\section{Divisions}

The vigour of the established Divisions hardly needs emphasizing with both Divisional and Sectional conferences having assumed an international importance. The high energy physics and the plasma physics conferences and the general conference of the Condensed Matter Division which was to follow close on the Council's

\section{Contents}

Council in Copenhagen

The Scientific Programme of JET

Hydrogen in Intermetallic Compounds

14th EGAS Conference

New Members of EPS

Amendments to the Constitution and By-Laws

Delegates of Individual Members
1

3

7

11

11

12

12 
heels (in Lausanne) are now part of the permanent scientific calendar.

Still to gather momentum is the Optics Division which was formed towards the end of last year under a provisional board. The forward programme of the Division needs to be cleveloped and relations with other organisations clarified. Other areas of physics which are under consideration are geophysics which needs to be related to the European Geophysical Society and (since several years) biophysics and medical physics. In the biophysics area, efforts are being made to form a special European Association and it was noted that in severa countries, biophysics did not figure in the ambit of the national physical society. Medical physicists on the other hand tended to be part of the physics community. In the coming year, further thought will be given to the problem and probably some scientific meetings arranged during which it can be discussed.

\section{Europhysics Letters}

At the last Council meeting the outlook for a new European general physics letters journal was not very promising, but the past year had seen a significant change and an understanding has now been reached between the representatives of the physical societies most directly concerned in the initial exploration, notably the French Physical Society, the Italian Physical Society and the UK Institute of Physics. According to this understanding, both the Journal de Physique Lettres and /I Nuovo Cimento Lettere would be suppressed and their subscription lists transferred while the Institute of Physics would divert general letters from the Journal of Physics and provide funds to make the equivalent capitalized sum of one journal. For symmetry it would not be excluded for the parent French and Italian journals to carry specialised letters but clearly no organisation participating in the project would be able to set up a competitive publication.
Scienfific control would lie entirely in the hands of EPS, the Executive Committee being responsible for appointing the chief editor and the editorial board which would also act as the panel of referees. Financia control would be in the hands of a board representative of the contributing bodies. For its scientific input, EPS would be considered to have a (say) $10 \%$ holding, but would not be required to pay any money.

Whereas the contributions of the three physical societies would be sufficient to launch the journal, conceived as being fortnightly, for both financial and scientific reasons, the participation of other national societies is highly desirable. Council therefore invited its group members to study as a matter of urgency the possibility of investing in this exciting new enterprise. Investment it should certainly be. There has been a rallying of physicists from all sectors including those who are on the whole satisfied with the present journal outlets and, if we can have the active support of a significant fraction of the physical societies, the journal should be making a profit in its third year, if not before. Naturally an investment implies a share holding which will carry a corresponding say in the management and a proportional share of the profits. The possibility of an input from individual members is also being examined with representation through EPS.

In the costings that have been prepared provision has been made for individual members of EPS to receive the journal for a nominal subscription and preliminary discussions have already been held on how the journal could be distributed in the countries with non-convertible currencies so as further to consolidate the concept of a journal that is really European.

Council applauded the progress that had been made and set a tentative date for receiving letters of intent from contributing societies as the end of this year with a launch date for 1 January 1985

\section{NATO Advanced Study Institute on NON-EQUILIBRIUM COOPERATIVE PHENOMENA IN PHYSICS AND RELATED FIELDS}

Cooperative phenomena manifest through non-linear laws in non-equilibrium systems: lasers (quantum optics), convective instabilities, thermoelasticity, flames, reaction-diffusion kinetics, nuclear processes, etc.

Open to participants from all countries.

Information and applications: Director of the ASI

Professor Manuel G. Velarde

U.N.E.D.-Ciencias

Apartado Correos 50.487, Madrid

Deadline for application: 31 May, 1983. 